\title{
EDUCAÇÃO E INVISIBILIDADE SOCIAL NA OBRA \\ QUARTO DE DESPEJO, DE Carolina Maria de Jesus
}

\section{Simone Cabral Marinho dos Santos* Nadia Farias Santos** Bruna Karine de Oliveira***}

Resumo: Este trabalho objetiva refletir sobre a obra Quarto de despejo: diário de uma favelada, de Carolina Maria de Jesus. Analisa-se o perfil de Carolina enquanto escritora, moradora de favela, catadora de papel e mulher negra. Nessa obra, escrita em forma de diário, a protagonista relata sua vida e o papel da educação e da escrita na desconstrução da condição de sujeito socialmente invisivel. Trata-se de uma narrativa de denúncia às condições precárias da vida na favela e de expressão da luta de Carolina por reconhecimento como escritora em busca de superação da sua condição de sujeito socialmente invisivel.

Palavras-chave: Literatura. Educação. Invisibilidade social.

\section{INTRODUÇÃO}

- arolina Maria de Jesus, em sua obra Quarto de despejo: diário de uma favelada, publicado em 1960, relata a sua comovente história de mulher negra, favelada e excluida socialmente. Em seus relatos, descreve sua rotina, o lugar onde vive, os seus vizinhos, a sua luta diária para conseguir o que comer e alimentar seus três filhos. Faz também uma crítica aos políticos e à falta de investimentos governamentais para os favelados.

Carolina foi descoberta pelo jornalista Audálio Dantas em uma visita à favela Canindé, onde ela morava, quando buscava conteúdo para uma reportagem. $\mathrm{O}$ jornalista surpreendeu-se ao ler os cadernos e percebeu que seus escritos ti-

\footnotetext{
Universidade do Estado do Rio Grande do Norte (UERN) - Pau dos Ferros - RN - Brasil. E-mail: simome.cms@hotmail.com

** Universidade do Estado do Rio Grande do Norte (UERN) - Pau dos Ferros - RN - Brasil. E-mail: nadia26farias@gmail.com

*** Universidade do Estado do Rio Grande do Norte (UERN) - Pau dos Ferros - RN - Brasil. E-mail: brun-hy-nha@hotmail.com
} 
nham muito a contar. Ela, então, tem seu diário publicado no formato de livro. Não é um simples diário, mas um relato de sua condição de catadora de papel, mulher, negra, mãe e invisivel para a sociedade.

O diário de Carolina é um instrumento de denúncia e poder, uma forma de se diferenciar dos demais favelados. As informações no diário, apesar de fragmentadas, se organizam em ordem cronológica com registro de datas com precisão na biografia da narrativa. Os relatos têm início em 1955 e fim em 1960, e trazem as transformações, decadências, descobertas e outros fatos vividos pela autora. Assim, a narrativa autobiográfica de Carolina nos conduz a uma reconstituição de sua vida.

Neste artigo, procuramos responder à seguinte pergunta: De que modo Carolina Maria de Jesus, na obra Quarto de despejo, desconstrói a sua condição de sujeito socialmente invisivel por meio da educação? O cerne da questão é exatamente o modo como Carolina busca a superação da sua condição de sujeito socialmente invisivel ao almejar seu reconhecimento como escritora, o que acontece com a publicação do seu livro. Ela ganha um grande número de leitores e causa surpresa ao agregar três aspectos pouco vistos juntos em escritoras contemporâneas à sua época: a condição negra, marginalizada e escritora.

Por esse viés, enquanto objetivo geral, buscamos refletir sobre o papel da educação na desconstrução da condição de sujeito socialmente invisível presente na obra de Carolina Maria de Jesus. E, como objetivos específicos, nos propomos a traçar um perfil da vida social e econômica da autora e refletir sobre o contexto histórico-educacional do período narrado por ela.

Ao falarmos de Carolina Maria de Jesus, estamos analisando várias temáticas, entre elas: educação, fome, miséria, desigualdades entre classes sociais, e focando na realidade de pessoas de classes economicamente desfavorecidas, os marginalizados descritos em Quarto de despejo. A trajetória de vida de Carolina enquanto favelada se repete até hoje, e, para essas pessoas, a educação é a melhor forma de desconstruir o processo de invisibilidade a que estão sujeitas.

\section{LITERATURA E NARRATIVA AUTOBIOGRÁFICA}

Embora não tenha concluído seus estudos, Carolina Maria de Jesus escrevia com frequência em seu diário. A forma literária que compõe a obra é o gênero diário, na narrativa autobiográfica. Em sua obra Quarto de despejo: diário de uma favelada, Carolina narra as reflexões sobre os momentos passados, descrevendo a favela e mostrando aspectos como: violência, fome e luta pela sobrevivência. Observa-se, em seus relatos, a repetição com que fala da busca cotidiana por comida, a catação de lixo nas ruas, a venda de papéis e ferros, sendo essas as maneiras como conseguia dinheiro para comprar alimento. Como define o texto abaixo:

Estendi as roupas rapidamente e fui catar papel. Que suplicio catar papel atualmente! Tenho que levar a minha filha Vera Eunice. Ela está com dois anos, $e$ não gosta de ficar em casa. Eu ponho o saco na cabeça e levo-a nos braços. Suporto o pêso do saco na cabeça e suporto o pêso da Vera Eunice nos braços. Tem hora que revolto-me. Depois domino-me. Ela não tem culpa de estar no mundo (JESUS, 1993, p. 19). 
Observa-se que o texto de Carolina é a representação do seu cotidiano. Ela fala de seus dias, expressa a fala de si e do outro (favelado). É independente, autônoma, guerreira e cuida sozinha dos filhos.

Mas, afinal, quem foi Carolina Maria de Jesus?

Nascida em Sacramento, Minas Gerais, em 14 de março de 1914, iniciou os seus estudos em 1921, no Colégio Allan Kardec, o primeiro colégio espírita do Brasil, onde permaneceu por dois anos. Neta de escrava, migrou para São Paulo em 1937, após a morte da mãe. Em 1948, foi morar na extinta favela do Canindé, na zona norte da cidade. Em São Paulo, trabalhou como doméstica, porém não se adaptou a esse tipo de serviço. Passou, então, a trabalhar como catadora de papel. Carolina nunca se casou e teve três filhos: João José de Jesus, José Carlos de Jesus e Vera Eunice de Jesus. Em 1969, mudou-se com os filhos para o sonhado sítio em Parelheiros, bairro da periferia de São Paulo (BARCELLOS, 2015).

Até aqui, temos uma história que poderia ser a de qualquer outra mulher brasileira pobre: negra, semialfabetizada, favelada, como tantas que existem no Brasil, não fosse por um detalhe: a paixão de Carolina Maria de Jesus pela leitura e escrita. Carolina dividia seu tempo entre catar papel, cuidar dos filhos e escrever. Em 1958, aparece a primeira reportagem sobre ela no jornal Folha da Noite. No ano seguinte, segundo Sousa (2011), é a vez de a revista O Cruzeiro divulgar o retrato da favela feito por Carolina.

Todavia, de acordo com Sousa (2011), Carolina só foi apresentada ao público em 1960, graças aos esforços do jornalista Audálio Dantas, que teve que enfrentar o desinteresse do mercado editorial da época pela literatura étnico-popular. Ao visitar a favela do Canindé para escrever uma matéria sobre a expansão do local, o jornalista conhece Carolina, que lhe entrega os manuscritos de seu diário. Surge, então, Quarto de despejo: diário de uma favelada, livro-diário em que a autora relata a fome cotidiana, a miséria, os abusos e os preconceitos sofridos por ela, seus filhos e outros moradores da favela. A primeira edição do livro alcançou a casa dos dez mil exemplares, esgotados em uma semana. Além disso, foi traduzido para vários idiomas, com sucessivas reedições, e adaptado para o teatro, para o rádio e para a televisão com grande sucesso de audiência.

Carolina Maria de Jesus publicou também: Diário de Bitita, Casa de alvenaria, Crônicas e Pedaços da fome. A obra Diário de Bitita, devido ao processo de silenciamento imposto pelo regime militar aos setores progressistas da sociedade, assim como ao preconceito intelectual da época, foi publicado primeiro na França (1982) e, anos depois, no Brasil (1986).

Carolina faleceu no dia 13 de fevereiro de 1977, aos 63 anos, em Parelheiros, devido a uma crise de asma (BARCELLOS, 2015; SOUSA, 2011).

\section{Literatura e sociedade}

Sabemos que, ao se tornar escritora, Carolina utiliza a literatura como uma forma de denúncia da sociedade. Escrevia fatos reais, uma visão de dentro da favela desconhecida pelas classes mais abastadas, as quais, segundo a autora, estavam na sala de visitas, enquanto ela, no quarto de despejo, a favela. Em toda sua narrativa, há a construção da oposição favela versus cidade, na qual a favela é "lama podre" e onde ficam os "excrementos". É um ambiente violento, pornográfico, sujo, sempre envolvido em brigas. É o lugar reservado ao "quarto de despejo". 
Por sua vez, a cidade é "perfume" e "flor". De acordo com Carolina de Jesus (1993, p. 85): "Quando eu estou na cidade tenho a impressão que estou na sala de visita com seus lustres de cristais, seus tapetes de viludos, almofadas de sitim".

Tomando como referência de análise o pensamento de Candido (2006), Carolina é a representação da literatura denunciadora dos grupos iletrados, pois, além de representar essa classe, traz também uma rústica parte da observação concreta dos fatos. Segundo Evaristo (2005, p. 205), "a escre (vivência) das mulheres negras explicita as aventuras e as desventuras de quem conhece uma dupla condição, que a sociedade teima em querer inferiorizada, mulher e negra".

Nesse sentido, Carolina percebe que seu diário é instrumento de denúncia da dura realidade enfrentada pelos pretos pobres, porque há nele sua visão de mundo, ou melhor, do seu lugar no mundo e na sociedade, do preconceito de todo dia, que certamente lhe desagrada, como expressa neste trecho: "Eu percebo que se este diário for publicado vai magoar muita gente, tem pessoas que quando me vê passar saem da janela ou fecham as portas. Estes gestos não me ofendem. Eu ate gosto porque não preciso parar pra conversar" (JESUS, 1993, p. 69).

Como afirma Candido (2006, p. 84), "a obra não é produto fixo, unívoco ante qualquer público; nem este é passivo, homogêneo, registrando uniformemente o seu efeito". Logo, no processo de atribuir sentido à escrita, a reação do outro motiva. Assim faz Carolina Maria de Jesus: diante das suas palavras, fica clara a sua autoconfiança, sua forma única de se expressar e de relatar, o que desperta a curiosidade nos seus leitores.

\section{A narrativa autobiográfica: diário e método narrativo}

O diário de Carolina teve muita importância, pois, além de apresentar relatos pessoais, serviu como testemunho de fatos sociais verídicos. Sua linguagem é a forma como uma marginalizada domina os códigos de uma classe social de letrados, bem como as limitações da escrita representam o lugar singular que ela ocupa na sociedade - lugar de exclusão.

Na contramão do acesso ao mundo letrado e culto, Carolina, segundo Fernandez (2015), constrói a voz autoral com incursões e experimentos em todos os gêneros e estilos, bem como uma série de intersecções entre os gêneros: drama (radionovela), provérbios, romances, poemas, sambas, entre outros. "É necessário entender a sua obra como um conjunto de criações variadas [...], fragmentando e improvisando sua produção quase a-estética, e sobretudo agramatical, de modo a revelar uma linguagem 'oculta' da lingua portuguesa" (FERNANDEZ, 2015, p. 316-317).

Observamos que Carolina reflete sobre a escrita e a literatura em seu diário, ela expõe seu pensamento sobre o mundo e a sua realidade por meio da narrativa autobiográfica. Os diários são fontes de muita informação sobre a realidade, têm uma escrita livre e subjetiva, um arquivamento dos fatos vividos na vida privada, o registro do cotidiano das experiências sociais e coletivas de uma população como testemunho histórico. Quando escreve sobre si, Carolina de Jesus (1993, p. 18) produz uma invenção literária a partir de experiências reais, objetivas e subjetivas: 
Deixei o leito as 4 horas para escrever. Abri a porta e contemplei o céu estrelado. Quando o astro-rei começou despontar eu fui buscar água. Tive sorte! As mulheres não estavam na torneira. Enchi minha lata e zarpei. [...] Fui no Arnaldo buscar o leite e o pão.

Segundo Lejeune (2008), o texto em forma de diário deve ser, principalmente, uma narrativa, afinal ela é estruturada nessa escritura. Além disso, destaca-se o caráter retrospectivo desse gênero: "isso não exclui nem seções de autorretrato, nem diário da obra ou do presente contemporâneo, nem construções temporais muito complexas" (LEJEUNE, 2008, p. 15). E, por fim, participam dessa composição a vida individual, a formação da personalidade e a história sociopolítica.

De acordo com Larrosa (2003, p. 11), a narrativa é um gênero discursivo por meio do qual o ser humano pode compor sua história, ao narrar fatos, enredos, acontecimentos. Nessa perspectiva, é central a discussão de como o texto narrativo serve de instrumento de construção da realidade. Na narrativa de Carolina de Jesus (1993, p. 20), a realidade é expressa a partir da sua visão de si e dos outros: "Aqui, todas impricam comigo. Dizem que falo muito bem. Que sei atrair os homens. [...] Quando fico nervosa não gosto de discutir. Prefiro escrever. Todos os dias eu escrevo. Sento no quintal e escrevo".

Segundo Arfuch (2002), a narrativa é concebida como uma modalidade de escrita que pode ser história ou ficção, e tanto a história pode conter ficção como a ficção pode conter história. Na escrita de Carolina, em forma de diário, há uma certa subjetividade da realidade em que ela vive e um modo de ler e interpretar a sua realidade tal como é. A necessidade de expressão de Carolina encontra a literatura como intermédio, por meio de relatos que trazem sua realidade subjetiva. De acordo com Viana (1995, p. 16):

A autobiografia, entendida como narrativa em que o autor, narrador e personagem são figuras coincidentes, não é certamente um gênero uniforme, sujeito a regras fixas. $O$ estilo ou a forma da narrativa autobiográfica pode se definir como maneira de cada autobiógrafo satisfazer as condições de ordem ética e relacional, que só exigem a narração verídica de uma vida [...].

Nesse contexto, a narrativa escrita em forma de diário é uma escrita do eu. Compõe-se em um discurso particular por meio do qual o escritor expõe fatos de sua história para uma reconstrução dela. De acordo com Maluf (1995, p. 29), rememorar é uma atividade orientada pela atualidade, e o narrador descreve suas vivências na perspectiva do presente, apoiando-se em "formas verbais para acomodar o passado tanto para si quanto para o leitor".

Miranda (2014) afirma que, na obra escrita por Carolina, há movimento literário de características fortes, como também uma tentativa de libertação dos modos de produção e de concretização de expressão livre. Na década de 1950, época da escrita de Quarto de despejo, textos como esse eram impressos em livros artesanais, mimeografados, com características do detalhe, da coloquialidade e das tiragens reduzidas. Em geral, distribuídos em bares e cinemas, e levados para as ruas e praças como meios alternativos de divulgação.

Segundo Henrique e Suliman (2012, p. 29), houve muitas mudanças ao longo do tempo na escrita de diário. Embora, segundo esses autores, atualmente, a 
escrita de diário esteja associada à condição feminina, "até o século XIX o número de homens que escrevia diários intimos era bem mais proporcional ao número de mulheres. [...] Somente no século XIX o diário íntimo passa a ter a conotação pejorativa de "coisa de mulher"'.

Nota-se que todos os formatos utilizados para a escrita de si registram o diálogo muitas vezes tenso dos indivíduos com seu tempo e lugar. Escrever diário é escrever história (HENRIQUE; SULIMAN, 2012). Assim justifica Carolina de Jesus (1993, p. 37) com suas palavras escritas em seu diário: "2 DE MAIO DE 1958. Eu não sou indolente, há tempos que pretendia fazer meu diário. Mas eu pensava que não tinha valor e achei que era perder tempo. [...] Eu fiz uma reforma em mim".

Uma marca do diário é a parcialidade, os escritos fragmentados. É um documento íntimo no qual escrevem todos aqueles que necessitam revelar sinceridades, sem recuo de limitar suas opiniões. Mas é justamente na promessa de sinceridade que repousa a fragilidade do diário, como citam Henrique e Suliman (2012, p. 31):

A fragilidade da noção de "sinceridade" que acompanha os diários íntimos reside na possibilidade dela tornar-se autoengano ou ser fruto de criação artística do sujeito que se pretende sincero, mas não faz mais do que criar uma impressão de verdade, relatando como realmente experimentado e vivido experiências baseadas na imaginação e no sentimento.

Para Henrique e Suliman (2012), temos que nos apropriar da dimensão social desse tipo de escrita de si. Quando o sujeito fala de si, há normas, valores, censuras impostos à época, cuja realidade social descrita é construída socialmente. Dessa feita, o conteúdo do diário é relacional, porque o indivíduo estabelece sua relação com o mundo. É justamente nesse ponto que nos apropriamos da escrita de Carolina e de sua relação com o mundo. Sua narrativa de vida é um retrato de muitos marginalizados que até hoje vivem em condições precárias de invisibilidade social.

\section{Contexto histórico, político e social da narRativa de Carolina}

Diferentemente de outros escritores famosos, Carolina Maria de Jesus se torna símbolo de contradições de projeto de modernidade nacional, visto que seu texto traz a problemática na cultura do discurso literário, gerando até mesmo desconfianças sobre sua literatura. O livro Quarto de despejo: diário de uma favelada é o que melhor representa a população pobre dentro de projetos de modernização no período em que foi escrito (segunda metade da década de 1950). Carolina se referia à favela como o quarto de despejo, onde se jogava aquilo que não se queria mais, que não possuía valor algum.

O diário foi escrito no período de 1955 a 1960. Foi contemporâneo ao governo de Juscelino Kubitschek (JK): época de promessas de progresso e de expansão do país, o chamado "período dos 50 anos em 5". Embora, na época, grandes obras estivessem sendo construídas, a situação da favela era crítica. Nas palavras da autora: "Juscelino esfola! Adhemar rouba! Janio mata! A câmara apóia! E o povo paga!" (JESUS, 1993, p. 116).

Na maior parte do seu texto, Carolina denuncia e critica os políticos por só aparecerem na época de eleições, por não fazerem nada pelos marginalizados. 
Tinha grande revolta por morar ali, sonhava em sair daquele lugar que denominava quarto de despejo. A falta de ações do governo para com essas pessoas não escapou ao olhar atento de Carolina. Observamos isso quando ela diz: "Quem governa o nosso país é quem tem dinheiro, quem não sabe o que é fome, a dor, e a aflição do pobre. Se a maioria revoltar-se, o que pode fazer a minoria? [...] Precisamos livrar o país dos políticos açambarcadores" (JESUS, 1993, p. 35).

Mais tarde, na década de 1960, a politica econômica desenvolvimentista tornou-se também marca do regime ditatorial (1964-1985). Por se tratar de um período de grande retrocesso para a democracia, de censura e de repressão social, Carolina teve seus textos rejeitados e extirpados do mercado editorial. Sua obra, segundo Barcellos (2015), dava visibilidade ao que deveria ser socialmente escondido: a pobreza do Canindé, favela situada às margens do rio Tietê, em São Paulo, justamente no período em que a ditadura militar procurava esconder os problemas sociais do país.

Do início ao fim, no diário de Carolina Maria de Jesus, há registros sobre o processo de urbanização em expansão na década de 1950 no Brasil e, com ele, os seus sentidos aguçados de desodorização do espaço urbano. Não por acaso, Carolina almeja a cidade, ao passo que denunciava o descaso governamental com a favela.

É de extrema importância destacar o tom de crítica política e social que Carolina de Jesus (1993, p. 27) faz, em seu diário, para denunciar a invisibilidade dos marginalizados sociais, relegados ao esquecimento e silenciamento no Brasil: "Hoje amanheceu chovendo. É um dia simpático para mim. É o dia da abolição. Dia que comemoramos a libertação dos escravos. [...] E assim no dia 13 de maio de 1958 eu lutava contra a escravidão atual a fome!".

A autora também descrevia em seu diário a angústia que ela e os demais marginalizados compartilhavam naquele mesmo ambiente e situação:

14 DE SETEMBRO. Hoje é o dia da pascoa de Moyses. O Deus dos judeus. Que libertou os judeus ate hoje. O preto é perseguido porque sua pele é da cor da noite. E o judeu porque é inteligente. [...] Já nos pretos não tivemos um profeta pra orar por nós (JESUS, 1993, p. 107).

Há uma inclinação, nos trechos citados em Carolina, para admitir que a diferença entre negros e brancos (embora ela trate de judeus) seja entendida como desigualdades naturais (providência divina). Mais do que isso, reproduz a condição social dos negros como seres inferiores, proporcionando a criação de um círculo vicioso que reforça a discriminação racial no cotidiano da favela. Em geral, Carolina de Jesus (1993, p. 38) mantém, em seus relatos, protestos contra a classe politica que nada faz para mudar as péssimas condições de vida dos desfavorecidos - os favelados: "um político diz nos seus discursos que está ao lado do povo, que visa incluir-se na política para melhorar as nossas condições de vida pedindo o nosso voto prometendo congelar os preços [...]. Depois divorcia-se do povo".

A situação governamental em nada favorecia os favelados, isso não passou em branco ao olhar de Carolina, os políticos tinham interesse apenas em seus votos e depois os abandonavam, decepcionando-os. Em seus registros diários, ela relata tudo que acontece na favela: fome, confusões, falta de direitos, diferenças, dificuldades em catar papel e ferro, falta de alimentos etc. Acordava cedo para pegar água e, em seguida, ia para a rua em busca de dinheiro. Nos dias chuvosos, havia mais dificuldade, não podia sair para catar papel, e, dessa for- 
ma, aumentava a fome; muitas vezes, catava até comida no lixo. Na favela, deparava-se constantemente com brigas dos vizinhos, miséria e violência.

Enquanto catadora, a autora escrevia em cadernos sujos que encontrava no lixo, os quais, depois de descartados, materializavam a precariedade dela e também eram citados como "objetos fora de uso" (JESUS, 1993, p. 38). Segundo Miranda (2014), Carolina Maria de Jesus migrou de todos os lugares que tentaram circunscrevê-la. De Sacramento, sua cidade natal, da favela do Canindé, das luzes da cidade do cetim. Só nunca migrou da escrita, pois esse foi sempre o seu lugar de pertencimento. Uma escrita marginal e contemporânea, da qual brota sua experiência, pois Carolina viveu como milhares à margem das benesses que o desenvolvimentismo e o progresso traziam para o país, mesmo quando, devido ao poder aquisitivo e à fama que havia conquistado, mantinha-se à margem da sociedade.

A margem é social, pois, sendo ela uma mulher negra, de pouca escolaridade, no meio da intersecção de raça, gênero e classe, não passou ilesa pelas estruturas racistas de nossa sociedade. De acordo com Alves (2010-2011, p. 186), "ao assumir sua voz-mulher, as escritoras afrobrasileiras ampliam o significado da escrita feminina brasileira, revelando uma identidade-mulher que não é mais o 'outro' dos discursos". A autora, ciente de que o poder tem cor, afirma: "Enfim, o mundo é como o branco quer. Eu não sou branca, não tenho nada com estas desorganições" (JESUS, 1993, p. 70).

\section{EduCAÇÃo E INVISIBILIDAde SOCIAL NA OBRA QUARTO DE DESPEJO}

No campo educacional brasileiro, em meados da década de 1950, o modelo econômico desenvolvimentista afetou diretamente a politica educacional. A diversificação das atividades econômicas criou oportunidades de novos empregos compativeis com niveis de escolarização mais elevados. Na prática, o mercado exigia uma mão de obra qualificada, mas o acesso à educação no Brasil permaneceu restrito e elitizado. Há uma exigência de qualificação de mão de obra para o mercado de trabalho em ascensão, ao passo que a manutenção da exploração da mão de obra é um modo de acumulação do capital. Nesse período, houve um crescente processo de migração para os grandes centros, como São Paulo, incompatível com o crescimento urbano ordenado, resultando no aumento do número de favelas (RIBEIRO, 2003).

Sabe-se que há uma real exigência de maior investimento na educação, para fins de diminuição do analfabetismo, que predomina, sobretudo, na população concentrada na favela. Embora o Plano de Metas de JK tivesse o objetivo de gerar o desenvolvimento em todo o território nacional, a educação ocupava lugar secundário. O setor da educação foi contemplado com poucos investimentos e abrangia uma única meta: formação de pessoal técnico, em consonância com a educação para o desenvolvimento (ROMANELLI, 1998).

Em se tratando de educação básica, a política educacional não alcançou maiores avanços, ficando o Estado alheio aos investimentos em educação pública, gratuita, laica e obrigatória. Na verdade, essa pauta seguiu levantada, quase exclusivamente, por educadores brasileiros conhecidos como pioneiros da educação, cuja luta pela universalização do ensino e erradicação do analfabetismo foi bandeira desde 1932. A principal luta desses educadores consistia na defesa da educação como direito, garantido pelo Estado, a todos os cidadãos que esti- 
vessem em idade escolar; defendiam também a obrigatoriedade da matrícula, a abolição do ensino confessional público e a gratuidade do ensino para todos, indiscriminadamente (RIBEIRO, 2003).

Com a promulgação da Lei de Diretrizes e Bases (LDB), em 1961, os defensores da Escola Nova não conquistaram a ampliação da rede oficial de ensino público, que marginalizava a população em idade escolar. Aprovou-se a expansão da rede privada, porém o conjunto da população mais carente não alcançou os beneficios dessa expansão. O combate ao analfabetismo foi secundarizado, numa realidade que amargava um percentual de 50,5\% de analfabetos, em 1950 (RIBEIRO, 2003). Já na década de 1960, os movimentos de educação popular surgiram em decorrência do interesse de que a população adulta tomasse parte ativa na vida política do país. Nesse período, entrou em cena o grande educador brasileiro Paulo Freire, referência na politização e na alfabetização de jovens e adultos no Brasil desde então.

As atitudes do novo governo ditatorial não se resumiram à inviabilização do que vinha sendo tentado até então. O governo concentrou-se no processo de privatização, no controle ideológico e político do ensino, bem como no descompromisso com o financiamento público e gratuito do mesmo (ROMANELLI, 1998).

\section{A escrita como lugar de resistência}

O refúgio de Carolina é a escrita, é também o que a torna sujeito de si mesma. A leitura e a escrita a diferem dos demais moradores da favela, uma vez que, escrevendo em todos os momentos em que tem tempo livre, a leitura vai fornecendo elementos reflexivos para a escrita, e ambas - leitura e escrita - funcionam como instrumento de interação com o mundo.

Dessa forma, a escrita para Carolina é um desabafo, é seu lugar de resistência. Escrever também se torna uma forma de defesa, pois ela ameaça escrever sobre seus vizinhos, denunciá-los. Assim, a escrita funciona, para Carolina, como uma maneira de mudar de classe social, e assim acontece quando é publicado o seu segundo livro Casa de alvenaria: diário de uma ex-favelada (JESUS, 1961). É por meio da escrita que Carolina dá significado à sua vida. Mesmo sendo vítima de preconceitos, ela relata com clareza as diferenças entre ser negra pobre e morar na favela. Relata as ofensas que sofria até mesmo das pessoas que viviam no mesmo lugar.

Fui na Dona Juana, ela deu-me pães. Passei na fábrica para ver se tinha tomates. Havia muitas lenhas. Eu ia pegar uns pedaços quando vi um preto dizer para eu não mecher nas lenhas que êle ia bater-me. Eu disse para bater que eu não tenho medo. [...]

Guando alguém nos insulta é só falar que é da favela e pronto. Nos deixa em paz. Percebi que nós da favela somos temido [...] (JESUS, 1993, p. 70).

Em sua defesa, Carolina chega até mesmo a fazer ameaças, para se livrar de certas situações. Ela escrevia em seu diário seus desabafos, a monotonia de sua vida, a sua indignação com os políticos, mostrava a realidade das diferenças sociais e era a voz da minoria, dos desclassificados que lutam para sobreviver em condições trágicas, um povo que é invisivel aos olhos da opressão.

O sofrimento e o senso de justiça dão a Carolina a sensibilidade da poesia. Favelada, batalhadora e sofrida, ganha visibilidade e muda radicalmente sua vida. A escrita torna-se o passaporte para a realização de seu sonho: sair da 
favela. A leitura e a escrita marcam sua vida. Em seus escritos, a invisibilidade da mulher negra fica bem evidente, mesmo depois do sucesso do seu livro, ela não teve o mesmo reconhecimento das demais escritoras da época. Pode-se supor que o país estava interessado apenas em conhecer a realidade do mundo que Carolina viveu, mas não em transformá-la. Ser negra era um obstáculo para Carolina. Em uma das passagens do livro, seu amigo do circo lamentava ela escrever tão bem, "pena ser negra".

Ao refletirmos sobre esse contexto literário, Santos (2012) ajuda-nos a pensar sobre o papel do sujeito no mundo por ele questionado e transformado, invertido e reconstituído cotidianamente como prova de sua consciência de si e de sua realidade. É do conjunto de experiências que o espaço se organiza e os sujeitos se autorreconhecem e reconhecem o outro na sua singularidade e originalidade.

Em Quarto de despejo, os relatos de Carolina trazem à tona a sua invisibilidade social e a do coletivo na favela, a falta de importância que é dada a eles, seres que sofrem indiferenças e preconceitos. Segundo Santos (2012), experiências de desrespeito social são perceptiveis sintomas de invisibilidade na medida em que os sujeitos se submetem a quadros de subordinação que os anulam e não os fazem ser notados.

Carolina também relata a condição de desvantagem educacional, assim como social e econômica, vivida por ela e pelos sujeitos que a rodeiam. De fato, o descaso com a educação contribuiu para o avanço das desigualdades sociais no país, mantendo a escola alheia aos problemas sociais. Na obra aqui analisada, observamos que Carolina se apresenta contrária às suas condições sociais. Os poucos anos em que esteve na escola lhe foram suficientes para continuar lendo tudo que chegava a suas mãos, e isso permitiu que escrevesse em cadernos que encontrava no lixo. Esse interesse pela escrita assenta-se no fato de a educação ser capaz de mediar as possibilidades de intervenção no mundo, em que os sujeitos saem da condição de observadores e se tornam sujeitos dessa realidade (SANTOS, 2012). É um movimento de "assumir-se como ser social e histórico como ser pensante, comunicante, transformador, criador, realizador de sonhos, capaz de ter raiva porque capaz de amar" (FREIRE, 1996, p. 41).

Morar na favela era um sofrimento para Carolina, que sonhava em sair de lá. Fez uso da palavra, mesmo que de maneira informal para mostrar a vida e a fome. Dessa forma, Quarto de despejo foi de grande importância, pois coloca em evidência a educação como denúncia dos problemas sociais, capaz de desconstruir a condição de invisibilidade social. Escritores como Carolina ganham representatividade quando registram sua própria história. Assim, ela nos alerta: "A vida é igual um livro, só depois de ter lido é que sabemos o que encerra. E nós quando estamos no fim da vida é que sabemos como nossa vida decorreu. A minha, até aqui tem sido preta. Preta é a minha pele. Preto é o lugar onde eu moro" (JESUS, 1993, p. 147).

Carolina é uma mulher negra, mãe solteira e favelada que usa a sua escrita para denunciar a elite e sua condição de sujeito socialmente invisivel e excluído do processo desenvolvimentista dos anos 1950. É a sua face de escritora que lhe dá destaque, mas sua vitória não é contra a fome, é contra o meio, a favela. Ela chama para si o direito de escrever, o direito à educação, o direito à moradia digna, ao trabalho, ao respeito e à dignidade da pessoa humana. 


\section{CONSIDERAÇõES FINAIS}

Nesse artigo, refletimos sobre o papel da educação na desconstrução da condição de sujeito socialmente invisivel presente na obra Quarto de despejo: diário de uma favelada, de Carolina Maria de Jesus, analisando o perfil de Carolina enquanto escritora, moradora de favela, catadora de papel e negra, vivendo em condições precárias da vida social.

No início do trabalho, observamos a presença da literatura na vida de Carolina, que, com poucos anos de estudo, não se distanciou da escrita, tornando-se, posteriormente, uma escritora. Discutimos sobre a narrativa autobiográfica e a escrita em forma de diário. Vale salientar que a literatura de Carolina se apresenta como uma forma de denúncia da sociedade, pois a mesma critica a falta de ações governamentais aos invisiveis sociais como ela.

Com essa reflexão, percebemos a condição de invisibilidade social vivida por Carolina Maria de Jesus quando amargava uma realidade de privações como fome, miséria e preconceito. Na obra Quarto de despejo, por um lado, são evidentes os sentimentos de desprezo e humilhação com os quais Carolina convive; por outro, coloca em evidência a denúncia, a luta pela sobrevivência e, acima de tudo, o olhar crítico perante a sua condição de sujeito socialmente invisivel. É dessa experiência de invisibilidade social oriunda tanto do lugar onde vive - a favela - quanto de suas precárias condições materiais - catadora de lixo - que Carolina confere à educação, enquanto prática social, o esforço para confrontar sua realidade e lutar para ser reconhecida como escritora.

\section{Education and social invisibility in Dump room, by Carolina Maria de Jesus}

Abstract: This paper aims to reflect on the work Dump room: diary of a slum, by Carolina Maria de Jesus. We analyze Carolina's profile as a writer, slum dweller, gleaner of paper and black women. In this work, written in diary form, the protagonist tells her life, the role of education and writing in the deconstruction of socially invisible subject condition. This is a complaint of narrative to the precarious conditions of slum life and expression of Carolina' struggle for recognition as a writer in search of overcoming their condition of subject socially invisible.

Keywords: Literature. Education. Social invisibility.

\section{REFERÊNCIAS}

ALVES, M. A literatura negra feminina no Brasil - pensando a existência. Revista da $A B P N$, v. 1, n. 3, p. 181-189, nov. 2010/fev. 2011.

ARFUCH, L. El espacio biografico: dilemas de la subjetividad contemporánea. Buenos Aires: Fondo de Cultura, 2002.

BARCELLOS, S. da S. (Org.). Vida por escrito: guia do acervo de Carolina Maria de Jesus. Sacramento: Bertolucci Editora, 2015.

CANDIDO, A. Literatura e sociedade. Rio de Janeiro: Ouro sobre Azul, 2006. 
EVARISTO, C. Gênero e etnia: uma escre (vivência) de dupla face. In: MOREIRA, N. de B.; SCHNEIDER, L. (Org.). Mulheres no mundo: etnia, marginalidade e diáspora. João Pessoa: Ideia, 2005. p. 201-212.

FERNANDEZ, R. A. Manuscritos inacabados: folhas esparsas em narrativas de gênese ou experimentos de uma obra. In: BARCELLOS, S. da S. (Org.). Vida por escrito: guia do acervo de Carolina Maria de Jesus. Sacramento: Bertolucci Editora, 2015. p. 316-328.

FREIRE, P. Pedagogia da autonomia: saberes necessários à prática educativa. 31. ed. São Paulo: Paz e Terra, 1996. (Coleção Leitura).

HENRIQUE, M. C. H.; SULIMAN, S. da S. Diário íntimo: fonte de pesquisa e instrumento pedagógico. Anuário de Literatura, Florianópolis, v. 17, n. 2, p. 27 44, 2012. Disponível em: <https://periodicos.ufsc.br/index.php/literatura/article/viewFile/2175-7917.2012v17n2p27/23259>. Acesso em: 15 jun. 2016.

JESUS, C. M. de. Casa de alvenaria: diário de uma ex-favelada. São Paulo: Francisco Alves, 1961.

JESUS, C. M. de. Quarto de despejo: diário de uma favelada. São Paulo: Ática, 1993.

LARROSA, J. La experiência de la leitura: estudos sobre literatura e formación. Buenos Aires: Fondo de Cultura Económica, 2003.

LEJEUNE, P. O pacto autobiográfico: de Rousseau à internet. Belo Horizonte: Editora UFMG, 2008.

MALUF, M. Ruídos da memória. São Paulo: Siciliano, 1995.

MIRANDA, F. R. de. A experiência literária marginal em três atos: o "maldito" dos anos 70, o "periférico" contemporâneo e a outsider Carolina Maria de Jesus. Estação Literária, Londrina, v. 12, p. 332-342, jan. 2014.

RIBEIRO, M. L. de O. História da educação brasileira: a organização escolar. 18. ed. Campinas: Editores Associados, 2003. (Coleção Memória da Educação).

ROMANELLI, O. de O. História da educação no Brasil. 21. ed. Petrópolis: Vozes, 1998.

SANTOS, S. C. M. dos. Nas veredas por reconhecimento social: o papel da educação na desconstrução da inferioridade dos sujeitos do campo. 2012. $264 \mathrm{f}$. Tese (Doutorado em Desenvolvimento Regional, Cultura e Representações)-Universidade Federal do Rio Grande do Norte, Natal, 2012.

SOUSA, G. H. P. de. Carolina Maria de Jesus: escrita íntima e narrativa de vida. In: BASTOS, H. J. de M.; ARAÚJO, A. F. B. (Org.). Teoria e prática da crítica literária dialética. Brasília: Editora da UnB, 2011.

VIANA, M. J. M. Do sertão à vitrine: memórias de mulheres. Belo Horizonte: Editora UFMG, 1995. 